\title{
Pervivencia del sustrato prerromano en el proceso romanizador de Hispania (el caso religioso)
}

\author{
A.M $M^{a}$ VÁzQuez Hoys y J. Del. Hoyo Calleja
}

La romanización fue ante todo un proceso de transformación. $Y$ todo proceso se enmarca en dos coordenadas: espacio y tiempo. Decir que la romanización no se lleva a cabo con la misma intensidad en todo el marco geográfico de la península hispánica, o que no sufre idéntica densidad a lo largo del tiempo, resulta evidente y no es novedad repetirlo. Esta diferencia es requerimiento de todo proceso. Pero el enfoque que queremos dar a algo de sobra conocido tiene en esta ocasión por base el testimonio de la religiosidad de los hispanos. ¿Puede este punto añadir algo a un tema tan historiado en extensos repertorios bibliográficos? Si, si con palabras recientes de G. Alföldy, el estudio "en lugar de contentarse con la descripción de los monumentos y de la distribución de uno u otro culto en una región, o bien con la enumeración de los monumentos de los distintos cultos en esta o aquella ciudad, tiene en cuenta las relaciones entre la religión por una parte y el conjunto de orden socio-político y socio-cultural por otra, sea en el ámbito de una ciudad, sea dentro del marco de una región o provincia del Imperio romano, considerando estas relaciones estructurales tanto en su naturaleza sincrónica como en su aspecto diacrónico". Es decir, considerando "los cultos como expresiones de la mentalidad y del comportamiento, y por esto, de la auto-conciencia de la sociedad o de los diversos grupos sociales que los cultivaban, teniendo en cuenta tanto su continuidad como sus cambios» 1.

Es estudio de la Religión romana en Hispania, emprendido hace años -entre otros-- por Vázquez Hoys ${ }^{2}$, ha demostrado precisamente la falta

ALFöLDY, G., "Tarraco y la Hispania romana: Cultos y sociedad" en Religio deorum. Actas del Coloquio Internacional de Epigrafía. Culto y Sociedad en Occidente (Tarragona, oct. 1988). Sabadell 1993, p. 7-8.

2 VAZQUez HoYs, A.M" La religión romana en Hispania. Fuentes epigráficas, arqueológicas y numismáticas. (Tesis doctoral defendida en 1974. UCM 114/82); id. (1988) "La Religión romana en 
de homogeneidad, a lo largo del tiempo, de los diversos cultos, sobre todo en cuanto a su implantación y arraigo en las diferentes regiones peninsulares se refiere. En la zona Sur-sureste, en toda la franja costera perteneciente a las provincias Baetica y Tarraconensis, se ha constatado la existencia de numerosos restos materiales norteafricanos ${ }^{3}$, prueba de la pervivencia del importante influjo oriental y púnico, ambos elementos claves para entender la formación del sustrato peninsular, sobre todo en la mencionada zona, además de las variadas influencias de origen mediterráneo (en el sentido geográfico del término), hecho cada vez más eviente. Este factor púnico, como han señalado C. González Wagner, M. Bendala y L. García Moreno ${ }^{4}$, no terminó con el fin de la dominación política cartaginesa, tras su derrota en la Segunda Guerra Púnica. Últimamente algunos autores como Gozalves han puesto de relieve este tráfico comercial entre Hispania y el Norte de África ${ }^{5}$.

La presencia de orientales en Hispania en época prerromana debió constituir buena base para el asentamiento y ubicación de nuevos elementos humanos de la misma procedencia, ya en época romana. Sus formas de cultura, economía, organización urbana, y también sus creencias religiosas, determinaron una parte esencial de la entidad hispana, que mantuvo su singularidad multiforme, a pesar de la progresiva romanización.

Hispania", Historia Universal de España y América (Rialp, Madrid, p. 405-455 y 458-460); y todos los trabajos reseñados en VÁzQUEz HoYs, A.M $M^{a}$ y DEL HoYo, J., "La Gorgona y su triple poder mágico (aproximación a la magia, la brujería y la superstición II)" Espacio, Tiempo y Forma Serie II, Historia Antigua, t. 3, 1990, p. 117-182, notas 72 y 96.

3 Sobre los monumentos funerarios en forma de cupae por toda España, fechados en los siglos $\|$-II d.C., de influencia africana, cf. JULIÁ, D., "Les monuments funéraires en forme de demicylindre dans la province romaine de Tarraconaise" en MCVI, 1965, p. 29-54 + XVIII pl.; MARINER, S., "Nuevas inscripciones latinas de España" AEA 28, 1955, p. 197-243; para la fecha de los monumentos, ib. "Los conjuntos epigráficos del Museo de Historia de la Ciudad" en Cuadernos de Arqueología e Historia de la Ciudad 2, Barcelona, 1961, p. 5-109; BALIL, A., “Una nueva necrópolis romana en Barcelona" Ampurias 17-18, 1955-56, p. 267-70; y DURÁN y SAMPERE, "Una vía Sepulcral romana en Barcelona" Miscellanea Barcinonensia I, 1962, pp. 43-49 y III, 1963, pp. 55-86.

Sobre las relaciones de Hispania con el norte de África en los tres últimos siglos de la República v. BLÁzQuez, J.Ma , en Saitabi 11, 1962, p. 21 ss. Sobre las torres de influencia africana cfr. ABAD, L. y BENDALA, M., "Los sepulcros turriformes de Daimuz y Villajoyosa: dos monumentos romanos olvidados" en Lucentum IV 1985, pp. 147-184.

4 González Wagner, C., Fenicios y cartagineses en la Península lbérica, Madrid 1983; Bendala, M., "La perduración púnica en los tiempos romanos. El caso de Carmo", Huelva arqueológica IV, Huelva 1982, p. 194 ss; id. “El final de la cultura ibero-turdetana y el impacto romanizador" en Actas de la Mesa redonda sobre la Baja época de la cultura ibérica, Madrid 1979, pp. 33-48, p. 35; Garcia Moreno, L., "Sobre el decreto de Emilio Paulo y la Turris Lascutana" en Actas de la reunión sobre Epigrafia hispánica de la época romano-republicana. Zaragoza 1986, pp. 195-216.

5 Gozalves, E., “Observaciones acerca del comercio de época romana entre Hispania y el Norte de África" AA 29, 1993, pp. 163-176. 
La preponderancia industrial y comercial de Oriente a la Antigüedad es manifiesta, pues en esa zona se hallaban los principales centros de producción y exportación de la época. El tráfico cada vez más intenso con Occidente trajo como consecuencia el establecimiento de comerciantes en Italia, Galia, países danubianos. África e Hispania, donde llegaron a constituir auténticos núcleos de población. Particularmente numerosos fueron los sirios, que se asentaron allí donde había posibilidades de obtener grandes beneficios con su actividad comercial. Sus colonias, diseminadas por todo el Occidente, sirvieron de apoyo a la propaganda religiosa de sus ideas ${ }^{6}$.

La facilidad de las comunicaciones proporcionó mayor número y amplitud de viajes. De este modo, se multiplicaron los intercambios, no sólo de productos, sino de hombres e ideas. Los cultos orientales siguieron las grandes rutas comerciales, transportados por comerciantes a las ciudades, por soldados hasta las fronteras y por esclavos al campo, y a familias acomodadas en zonas urbanas y en la administración pública ${ }^{7}$. La onomástica de gran parte de esclavos y libertos con registros orientales y norteafricanos nos revela este aporte de gentes del otro lado del Mediterráneo en Hispania. La presencia de cognomina como Maurus por ejemplo, frecuente en el sur de la Península (a sabiendas de que éste es un sistema no seguro para la indentificación de movimientos migratorios) o bien de personas que indican su origo ${ }^{8}$ como Vibia Modesta, or(iunda) Mauretania ${ }^{9}$, nos invita a estudiar el tráfico de hombres que penetraron en Hispania en la Antigüedad, de todas esas gentes que llegaron a la Península con idea de comerciar y se fueron quedando a vivir.

Cf. Cumont, F., Las religiones orientales y el paganismo romano. Madrid 1987, p. 131.

MuNoz, J., ha demostrado (El culto de Mithra en Hispania: Caracteres especificos. Tesis doctoral inédita. UNED, Madrid 1989) la importancia de estas comunidades orientales, y sobre todo su economía, en la introducción y mantenimiento del culto de Mithra en la Península lbérica. Muchos comerciantes, hombres libres, esclavos, y sobre todo ricos libertos, debieron llegar a Hispania atraídos por la riqueza generada por los negocios hispanos. Estos elementos humanos, aunque formando parte plenamente de la sociedad hispanorromana, no habrian perdido sus antiguas formas de vida, y mucho menos sus creencias. Debieron ser acogidos por antiguas comunidades orientales asentadas en Hispania, compartiendo costumbres, tradiciones y cultos que les eran propios.

V. también VÁzQUEZ HoYs, A.M ${ }^{a}$., "La tradición religiosa del mundo mediterráneo en la Bética y la percepción de los cultos romanos", Actas del I Congreso Internacional sobre el Estrecho de Gibraltar, (Ceuta 1987) Madrid 1988, p. 845-853; ib. "La religión romana en la Bética y el sustrato prerromanon, I Coloquio de Historia de Andalucía (Córdoba, 6-9 abril 1988). Córdoba 1993, pp. 189-197.

a En LASSÉre, J.M., Ubique populus, París 1977, se muestra un considerable número de personas que, a través de la origo, sabemos que han tenido frecuentes relaciones entre el sur de Hispania y Norte de África. Ct. también MARION, J., "Note sur le peuplement de Tanger à l'époque romaine" Hespéris XXXV, 1948, p. 132-133.

9 Canto, A., La epigrafia romana de Italica (tesis doctoral xeroc.), Madrid 1985, 22 ter, p. 179-172. 
El sustrato prerromano de cultura orientalizante asentado en Hispania siguió influyendo en época imperial. ¿Puede decirse, por ello, que elementos religiosos orientales, mediterráneos, norteafricanos o púnicos, presionaron sobre los dioses del panteón romano, de forma que éstos encontraron resistencia a su implantación, especialmente Júpiter? La respuesta no puede ser un Sí tajante. Sin embargo, al estudiar su culto en Hispania, ya señalaba Vázquez Hoys hace años la desproporción del número de fuentes en las tres provincias hispanorromanas, y la extrañeza que causaba la escasez de inscripciones halladas en la Bética respecto a la Tarraconense y Lusitania ( $9 \%$ del total de la epigráfia hispana ${ }^{10}$ dedicada a Júpiter $\left.{ }^{11}\right)$. Apuntaba entonces, siguiendo en parte a Peeters ${ }^{12}$, como posibles causas:

- la mayor densidad de población, con un urbanismo más desarrollado, lo que pudo motivar una reutilización de materiales para edificios posteriores, entre ellos algunos elementos religiosos (aras, pedestales...)

- la presencia de numerosos cuerpos militares en Lusitania, Gallaecia y Asturias ${ }^{13}$;

- el número proporcionalmente mayor de colonias romanas o latinas en la Bética que en Tarraconense y Lusitania;

- la posible destrucción sistemática por parte de los cristianos de elementos visibles del culto pagano ${ }^{14}$.

Pero estas hipótesis no son fácilmente sostenibles, como ya apuntaba la misma autora. Aunque es cierto que la Bética tenía en términos globales y cifras generales mayor número de municipios y ciudades ${ }^{15}$ que las otras dos provincias hispanas, mayor densidad de población que en la Lusitania

10 VÁzQUEz HoYs, A.M $\mathrm{M}^{\mathrm{a}}$, “El culto a Júpiter en Hispania” CFC XVIII, 1983-84 pp. 83-205. Aunque el estudio ha quedado muy desfasado por la gran cantidad de material aparecido durante estos últimos años, sin embargo las inscripciones que se han ido publicando confirman hoy más aún que hace diez años esa desproporción mencionada de la Bética respecto a las otras dos provincias hispanas (v. AE 1982 ss., y HEp 1, 2, 3 y 4); Id.: Diana en la religiosidad hispanorromana I. (Las fuentes. Las diferentes diosas). Madrid, 1995, Introducción.

11 Falta un trabajo serio que suponga una puesta al día del culto de Júpiter en Hispania, tras el estudio cit. supra de VÁzQuEZ HoYs. Hace años se encontraba elaborando una tesis doctoral, muy prometedora en cuanto a metodología y conclusiones, P. PÉAuD. Parece que ha quedado interrumpida. Tan sólo conocemos su artículo "Le culte à Jupiter en Andalousie: pour une méthodologie de l'étude du Jupiter Hispanique" Actas del / Coloquio de Historia Antigua de Andalucia (Córdoba 6-9 abril 1988). Córdoba, 1993.

12 "Le culte de Jupiter en Espagne d'après les inscriptions" en RBPh XIII 1936, p. 158 ss.

13 Peeters, p. 160, nº 1 .

14 Causa que acepta y confirma BlÁzouEz, J.Mํa en La romanización (Istmo. Madrid 1974) 113-114.

15 Thouvenot, R., Essai sur la province romaine de la Betique (BEFAR, Paris, 1973). 
y Tarraconense occidental un urbanismo, al menos tan desarrollado, podemos encontrar en gran número de ciudades de la Tarraconense del litoral levantino, como Tarraco, Barcino, etc., donde no se conservan inscripciones a Júpiter o son escasas ${ }^{16}$.

Por otra parte, tampoco se ve bien la relación entre el culto a Júpiter y la acomodada posición económica de sus devotos, ya que muchas veces el ofrecimiento es una pequeña ara ${ }^{17}$. A menudo el material es pobre, como la arenisca o el granito (así la mayoría de las aras halladas en los conventus del noroeste hispánico, ofrecidas en muchas ocasiones por personajes que portan onomástica indígena, lo que tal vez indica que la divinidad está sincretizada) y los dedicantes son en ocasiones esclavos ${ }^{18}$.

En cuanto a la actividad iconoclasta por parte de la cultura cristiana, teniendo en cuenta la rápida difusión del cristianismo por toda la Península, cabe preguntarse por qué no se destruyeron también los vestigios de civilización pagana en Lusitania y Tarraconense ${ }^{19}$.

Por ello queremos anotar como factores determinantes -entre otrosdel descenso de dedicaciones a divinidades del panteón grecorromano, aparte de una posible razón cultural (una población más instruida pudo dejar de lado un sentimiento de dependencia respecto de los dioses), el auge del culto imperial y el sustrato prerromano.

1. Culto imperial. De los cuatro grandes bloques temáticos en que pueden distribuirse los distintos testimonios referentes a cultos de la Hispania romana ${ }^{20}$ :

- religiosidad tradicional grecorromana,

- culto imperial ${ }^{21}$,

16 Véase a este respecto el interesante artículo de ALFöLDY, G., "Bildprogramme in de römischen Städten des Conventus Tarraconensis. Das Zeugnis der Statuenpostamente» Revista de la Universidad Complutense (Homenaje a A. GARCIA y BELLIDO) XXVIII, 1979, pp. 177-275.

17 Arula rudis de arenisca, hallada en Tarraco (C/L II 4278), por poner sólo un ejemplo.

18 A propósito de este tema véase el trabajo de DeL. Hoyo, J., "Relación culto / estrato social en la Hispania romana» en Religio Deorum. Actas del Coloquio Internacional de Epigrafia. Culto y sociedad en Occidente (Tarragona, oct. 1988) Sabadell, p. 303-308.

${ }_{19}$ Precisamente los restos que han quedado indica más respeto que destrucción sistemática. Sí es cierto que ésta se ha producido, pero generada en siglos y por culturas subsiguientes.

20 Prescindimos intencionadamente del cristianismo, por presentar caracteristicas muy distintas.

2t Es de consulta obligada para Hispania, a pesar del atraso que ha sufrido con el paso de los años, la obra de EtIENNE, R., Le culte impérial dans la Péninsule lbérique d'Auguste au Dioclètien (BEFAR, París 1958). Las publicaciones de estos últimos años sobre este tema han sido ingentes y 
- cultos indígenas ${ }^{22} \mathrm{y}$

- divinidades mistéricas y orientales ${ }^{23}$,

es precisamente el culto imperial el único que se hace oficial ${ }^{24}$. En un momento en que la religión tradicional habia sufrido un serio desgaste y no proporcionaba a sus ciudadanos resortes vitales, fue el culto al Emperador el que permitió escalar posiciones en la administración pública. En efecto, el flamen municipal llega a este cargo después de haber recorrido el cursus honorum propio de ciudadanos romanos del tercer ordo y está en condiciones óptimas, aunque no sea conditio sine qua non, para acceder al flaminado provincial. El flamen provincial es elegido en una asamblea en la que participan representantes de todas las colonias y municipios de la provincia, lo que supone -como apuntaba hace años Sánchez Albornoz- un factor de unidad en el seno de cada provincia ${ }^{25}$. Dota además a sus representantes de un prestigio social envidiable. La Lex Concilii Provinciae Narbonensis (CIL XII 6038) establece una serie de privilegios para el flamen provincial:

- Puede revestir una vestimenta de color blanco o púrpura los días de fiesta,

no podriamos nunca ser exhaustivos. Pensemos simplemente que la bibliografía de tan sólo veinte años sobre el tema ocupa nada menos que 80 páginas de un repertorio (HERz, P., “Bibliographie zum römischen Kaiserkult (1955-1975)" en ANRW II, 16.2. 1978, p. 833-910). Afortunadamente siguen elaborándose anualmente monografías y tesis doctorales.

22 Deben verse las obras de BLÁzQUEZ, J.Mä., Religiones primitivas de Hispania (CSIC, Madrid 1961); id. Diccionarios de las religiones primitivas de Hispania (Madrid 1975); id. Imagen y mito. Estudios sobre religiones mediterráneas e ibéricas (Cristiandad, Madrid 1977); id. "Einheimische Religionen Hispaniens in der römischen Kaiserzeit" en ANRW II, 18.1, 1986, p. 164-275; id. Las religiones primitivas de la España romana (Madrid 1991; recopilación de sus últimos artículos y puesta al dia de todos sus trabajos).

23 Tan sólo disponemos de una obra de conjunto sobre el tema, la de GaRCiA y BELLIDO, A., Les religions orientales dans l'Espagne romaine (EPRO, LEIDEN 1967). Aparte de este trabajo, tenemos que recurrir a obras parciales, con mejor tratamiento de cada dios en particular, mayor crítica de las fuentes y puesta al dia integrando todos los hallazgos que desde entonces se han venido produciendo. Además del artículo de BENDALA, M., "Die orientalischen Religionen hispaniens in vorrömischer und römischer Zeit" en ANRW II, 18.1, 1986 (entregado el original en 1976), p. 345-408, deben considerarse los trabajos monográficos de ALVAR, J., publicados durante estos últimos años, especialmente "Cinco lustros de investigación sobre cultos orientales en la Península lbérica" Gerión 11, 1993, p. 313-326, donde hace una interesante puesta al día del tema, aunque con omisiones graves y la tesis doctoral de MuNoz, J., cit. en nota 7.

${ }^{24}$ Según la ya célebre cita de Tácito $(A n n, 1,78)$ parece que el culto imperial comenzó a rendirse en Tarraco y de aqui se extendió al resto de las provincias: "[...] templum ut in colonia tarraconensi strueretur Augusto petentibus Hispanis permissum datunque in onnes provincias exemplum". Acerca de este texto, v, el comentario que hace D'oRs, A., "Sobre los orígenes del culto al emperador en la España romana", Emerita X, 1942, pp. 197-227.

25 SÁnChez Albornoz, C., "El culto al emperador y la unificación de España", Anales del Instituto de Literaturas Clásicas III, 1946, p. 5-120. 
- No puede ser obligado a jurar,

- Le está prohibido tocar un cadáver humano,

- Tiene plaza reservada en los espectáculos públicos que acompañan a la celebración de culto ${ }^{26}$.

Además, cuando cese en su cargo (es anual), tendrá el privilegio de que se le erija en el recinto del templo de Augusto una estatua en cuyo pedestal se han de especificar los tria nomina, la filiación, origo, el cargo y en qué año ha desempeñado el ministerio ${ }^{27}$. El ejercicio del sacerdocio suponía un honos al que aspiraban las familias mejor situadas de cada municipio. Estaban exentos de los munera públicos y constituían un grupo privilegiado dentro de las élites urbanas, pues eran los únicos que podían hacer extensivos a los hijos numerosos privilegios, destacando por encima de algunos magistrados.

No es de extrañar, pues, que determinadas familias persiguiesen obtener el flaminado provincial o municipal, alcanzándolo algunos miembros dos y más veces ${ }^{28}$. Ejercian de esta forma un influjo social que no hubieran podido desarrollar por otros medios (la mujer, por ejemplo, no podía desempeñar sino cargos religiosos, estándole vedadas las magistraturas civiles y todos los officia virilia ${ }^{29}$ ). Es interesante observar asimismo cómo estos flamines y flaminicae ejercen a veces su cargo en distintos municipios. Así Porcia M.f. Materna es [fl(aminica] p(rovinciae) H(ispaniae) c(iterioris) et postea osicerd(ensis), caesar[aug(ustana)], tarrac(onensis) perpetua (CIL II 4241); Flavia L.f. Rufina es flaminica col(oniae) emeritensis perpet(ua) et municipi(i) salaciensis (CIL II 32); Valeria C.f. Paetinia es sacerdos coloniae patriciae cordubensis, flaminica coloniae aug(ustae) gemellae tuccitanae, flaminica siue sacerdos municipi(i) castulonensis (CIL II 3278) y Licinia Q.f. Rufina es sacerdos perpetua in col(onia) c(laritate) lul(ia) et in munici(pio) c(ontributo) ipsc(ense) et in munic(ipio) flor(entino) lliberrit(ano) (CIL II 1562).

Debemos señalar - para terminar este apartado-que municipios donde se han conservado varios testimonios de sacerdotisas del culto

\footnotetext{
26 Algunas de estas prerrogativas están tomadas directamente de las que gozaba el flamen dialis en Roma. De ellas nos informan Plutarco, Quaestiones romanae 109-113 y Aulo Gelio, Noctes Atticae X, 15.

${ }^{27}$ Nomen suum patrisque et unde sit, et quo anno flamen (CIL XII 6038, 12). Este último punto, el año en que desarrolló su cargo, no se observa en las provincias hispanas.

${ }_{28}$ En ltalica, por poner un sólo ejemplo, Vibia Modesta fue bis flaminica y sacerdos (LEÓN, P.: "La zona monumental de la noua urbs", I Coloquio sobre Itálica, Madrid 1982, p. 188 ss, n² y lám. 12,2).

29 Propios del varón, como los de juez, abogado, procurador o banquero (asi señalados por los Dig. L, 17,2 y II, 13,12 respectivamente.
} 
imperial (así Ipsca y Cartima en la Bética, por ejemplo) no presentan ni un solo epígrafe dedicado a Júpiter. Si superpusiéramos dos mapas de la Hispania romana, uno con las dedicaciones a Júpiter y otro con los epígrafes que testimonian el culto imperial, observaríamos su complementariedad, lo que viene a confirmar la idea que venimos exponiendo ${ }^{30}$.

2. Sustrato prerromano. Si se considera que la presencia romana en la Península, en un principio, debió responder principalmente a razones económicas, manteniendo en lo posible las estructuras anteriores ${ }^{31}$, habrá que señalar con $\mathrm{M}$. Bendala que "el sentido que, al progreso cultural, imprime Roma, enlaza con la trayectoria anterior sin cesuras aparentes", aprovechando aquellos elementos que servían a sus propios intereses y desinteresándose por los demás, entre los que estarían los religiosos ${ }^{32}$.

Esta continuidad de elementos orientales en la Península lbérica en época romana, debió constituir una base firme para la pervivencia de las tradiciones que les eran propias, constituyéndose en un sólido punto de apoyo para el asentamiento y reafirmación de nuevos elementos humanos afines.

Los trabajos de $M$. Ponsich y $M$. Tarradell sobre el "Círculo del Estrecho" o los de F. Kock, M. Bendala y O. Arteaga señalando la permanencia del elemento púnico en la Bética hasta bien avanzada la época de la dominación romana, ya señalados por Vázquez Hoys ${ }^{33}$ parecen responder a una realidad incuestionable. Ha de indicarse, además, la existencia de estrechas relaciones tipológicas entre el monetario libiofenicio y el norteafricano postpúnico, así como su dependencia gaditana, la

30 Encontrariamos como excepciones, evidentemente, las tres capitales de provincia y grandes núcleos de población que han recibido una romanización más intensa, siendo muy significativo el caso de Mérida.

31 FERRER, J., El Estado y la participación privada. Los inicios del régimen provincial romano en Hispania. (Tesis doctoral inédita. Valencia 1987). Para el estado actual de la cuestión, ct. Gonzalez Wagner, C., op. cit., en nota 3. También Niemeyer, H.G., dir.: Phöniquen im Western. Mainz am Rhein 1982.

32 BENDALA, M., «El final de la cultura ibero-turdetana" cit. en $n \div 3$, p. 35

33 ARteaga, O., "Anotaciones acerca de la dinámica histórica del poblamiento fenicio-púnico en Occidente a la luz de las excavaciones arqueológicas en el Cerro del Mar" Actas de la Mesa Redonda sobre la Baja Época lbérica. Madrid 1981, pp. 157-179. Utilizaremos aquí el término púnico en el sentido que lo hace O. ARTEAGA: “De la manera más generalizada y aunque pueda parecer inapropiado, queremos referirnos también al poblamiento que, sin ser cartaginés, podia haber formado un sustrato semita con fuerza suficiente como para pervivir durante siglos en las tierras abarcadas por las antiguas colonias fundadas por los fenicios en las costas del Mediterráneo oriental». Véanse también los últimos trabajos en el tomo I de las Actas del / Congreso El Estrecho de Gibraltar cit. en $n^{\circ} 5$ y la reafirmación de esta tesis en VÁzouez HoYs, A. Mª, Diana cit., pp. 15-28. 
existencia de una toponimia púnica bastante acentuada en esta zona del Mediterráneo peninsular, señalada por J. M. Solá ${ }^{34}$, o la persistencia en toda el área sur de la Península, de la antroponimia púnica y su posible irradiación a zonas marginales e indígenas e incluso las ánforas de tipología púnica, pero fabricadas ya en Hispania tras la destrucción de Cartago ${ }^{35}$.

Debe recordarse asimismo que, cuando lo púnico actúa sobre la Península, la influencia helenística sobre Cartago y su civilización, y la ocupación de la Península lbérica por los Bárquidas y posterior conquista por los romanos se hallan insertas en el jugo hegemónico de potencias de corte helenístico, cuyas formas de acción militar y política también se desarrollan en Hispania ${ }^{36}$.

El estudio de las formas de vida colectiva y de las manifestaciones religiosas corren a menudo el riesgo de quedarse en una simple abstracción erudita. Por eso, en los aspectos exteriores de la piedad popular ${ }^{37}$, es posible hallar las convergencias de diversas tradiciones y experiencias, reflejo de las condiciones existentes, de los fundamentos psicológicos más remotos $y$, a veces, de las ocasiones menos fortuitas, para comprender la solución religiosa que el hombre ha tratado de dar siempre a los problemas del mundo.

En cuanto a la pervivencia del sustrato prerromano ${ }^{38}$ como factor de resistencia a la romanización, pueden rastrearse en el campo religioso, y

34 "A propósito de nuevas y viejas inscripciones feno-púnicas de la Península Ibérica" Homenaje a A. Garcia y Bellido I, 1976, pp. 175-198.

35 GaRcia Bellido, M.P., "Leyendas e imágenes púnicas en las monedas libio-fénices" en Veleia 2-3 1987, pp. 499-519; $\mathrm{KOCH}, \mathrm{M}$., "Observaciones sobre la permanencia del sustrato púnico en la Península lbérica" Actas del / Coloquio sobre lenguas y cultura prerromanas de la Península Ibérica. Salamanca 1976, pp. 191-199; GARCíA MORENO, L., op. cit. en n 3, p. 207; BLECH, M., "Esculturas de Tajo Montero (Estepa): Una interpretación iconográfica" en Actas del Symposio sobre la religión romana en Hispania, Madrid 1981, pp. 97-110. VÁZOUEZ HoYs, A.M"a "EI templo de Hércules-Melkart de Cádiz y su papel económico" en Estudis d'Historia Económica, Economia y Societat en la Prehistoria y Món antic. Palma de Mallorca, 1993, 1, pp. 93-113. Son las Mañá C-1, púnicas, y la C-2, fabricada ya en Hispania con técnicas y, posiblemente, artesanos púnicos que huyen de la destrucción de Cartago por parte de Roma.

36 BENDALA, M., en Actas de la mesa redonda sobre la Baja Época ibérica, p. 36 . Sobre otras persistencia púnicas en el Mediterráneo, cf. TORE, G., «Di alcune stele funerarie dal Sinis: persistenze puniche di età romana in Sardegna ed in África" África romana II, 1985, pp. 135-146. VÁzOUEZ Hors, A.M": "El comercio entre Hispania y Mauritania y el templo de Hércules Melkart en Gades en época de luba II y Ptolomeo", Actas // CIEG, Ceuta, 1990, Madrid, UNED, 1995, pp. 329-342. Podría afirmarse, con estos presupuestos, que el inicio del culto imperial en Tarraco podría deberse a estas influencias helenísticas unidas al sustrato hispano del "culto al jefe".

${ }_{37}$ De la Ruelte, E., La pieté populaire au Moyen Âge, Torino 1975, prólogo de E. Manselli. También Le Bras, G., Studi di sociología religosa. Milano 1969 cit. por GioRdano, O., Religiosidad popular en la Alta Edad Media, Madrid, 1983, p. 8, n² 3 .

38 Sobre la pervivencia de elementos semitas, véanse las obras reseñadas en el trabajo de Pellicer, M., Menanteau, L, y Rulllard, P., "Para una metodología de localización de colonias 
sobre todo en la Bética, algunos casos significativos. En esta provincia, la divinidad más representada en los mosaicos romanos es DionysosBaco ${ }^{39}$, mientras que su epigrafía es escasa ${ }^{40}$. A este respecto, debe recordarse que el dios griego del vino y de la fecundidad, así como de la muerte y resurreción ${ }^{41}$, asimilado al Liber Pater romano desde un primer momento ${ }^{42}$, estaba asociado en Cartago a Tanit y Ba'al Hammon, explicándose esta asociación, no como una asimilación directa de ambos dioses masculinos sino que, al lado de Ba'al, existian una serie de divinidades secundarias y Dionysos pudo tomar fácilmente un lugar entre ellas. Como señalaba J. del Hoyo recientemente, podemos hablar de un Liber

fenicias en las costas ibéricas: El cerro del Prado", Habis 8, 1977, pp. 217-251, sobre todo pp. 217 227. Para los nuevos descubrimientos, cf. los trabajos realizados por el Instituto Arqueológico Alemán de Madrid en la zona de Torre del Mar, SchuBART, H., "Las excavaciones de Torre del Mar y el panorama arqueológico de las fundaciones de colonias en la costa mediterránea de la Península Ibérica" Papeles del Laboratorio de Arqueología de Valencia 11, 1975, pp. 199-206, donde se recoge la bibliografía hasta los años setenta. Para la investigación posterior, cf. MM 16-19, pp. 1975-78.

Sobre la pervivencia del sustrato púnico, ct. GaRCia y BelLIDO, A., Fenicios y cartagineses en Occidente, Madrid 1942. Estudios más recientes los de KoCH, M., op. cit. y BLAZqUEZ, J. Mã Economia de la España prerromana, Bilbao 1978, 634 y siguientes; id. Tartessos 2, Salamanca, 1975.

39 Sobre la presencia de este dios en Hispania, véase la tesis doctoral de Garcia SANZ, O., Baco en Hispania. Economía y religión a través de las fuentes epigráficas, arqueológicas y numismáticas (Madrid. UCM 233/90), donde presenta 319 piezas, algunas de ellas inéditas y supone una puesta al dia sobre el tema. No obstante, hoy dia podemos hablar ya de más de 400 testimonios. Un trabajo reciente de BERnAL, D. y GARCía SANZ, O., "Iconografía dionisíaca en lucernas de la Hispania romana" (en prensa en CUPAUAM) estudia 87 lucernas de tema báquico, si bien sabemos que este tipo de piezas no indican realmente culto al dios. Sobre los mosaicos báquicos, cf. BLȦZUEZ, J.Mํ, Mosaicos romanos de Sevilla, Granada, Cádiz y Murcia. Corpus de mosaicos de España fasc. IV, 1978, p. 13 ss. con abundante bibliografía y "Mosaicos dionisiacos de Hispania", cap. III de Mosaicos romanos de España. Cátedra. Madrid 1993, pp. 275-332.

${ }_{40}$ Disponiamos tan sólo de tres ejemplos, $C / L I I 1108,1109$ y 2105, a los que hay que sumar el importantísimo hallazgo en el foro de Hispalis, (CAMPOS, J. y GonzÁLEZ, J., "Foros de Hispalis" $A E A 60,1987$, pp. 130-133. Se trata de un fragmento de placa de mármol blanco de grandes dimensiones $(44 \mathrm{~cm} \times 90 \mathrm{~cm} \times 5 \mathrm{~cm}$ ) y está dedicada por un collegium, único caso en Hispania. Se trata de [uinajri según los autores, de [scaphajri, según AE 1987. Como observa CANTO, A., "seria posible restituir cualquier oficio relacionado con la producción o el comercio del vino" (HEP 3 , 1993, 353). Sobre Liber Pater en la epigrafia hispana, veánse los trabajos de DeL HoYo, J.: "Liber Pater dans l'épigraphie hispanique: relations entre la viticulture et le culte du dieu" Caesarodunum XXIV, 1990, pp. 199-122; y "Revisión de los estudios de Liber Pater en la epigrafía hispana" eb MCV XXVIII/1, 1992, pp. 65-92.

${ }_{41}$ Aspecto éste a menudo olvidado. Véase al respecto la obra de BURKERT, W., Homo necans. The Anthropology of Ancient Greek Sacrificial Ritual and Myth (Los Ángeles 1983) y el reciente estudio de VELASCO, $\mathrm{M}^{2} \mathrm{H}$., "Le vin, la mort et les bienhereux (à propos des lamelles orphiques)" en Kernos 5, 1992, pp. 209-220, donde la autora estudia la vinculación de dos laminitas de oro halladas en 1985 en Petroporos, precisamente con Dionysos.

${ }_{42}$ Sobre Liber Pater en general, v. la monografía de BRUHL, algo anticuada por el cúmulo de testimonios aparecidos durante los últimos años, Liber Patr, Origine et expansion du culte dionysiaque à Rome et dans le monde romain (BEFAR 175, Paris 1953). 
Pater epigráfico, resultado de corrientes sincretistas, en el que se juntan el Liber itálico, el Dionysos-Baco del panteón grecorromano y la divinidad indígena propia de cada región o provincia, como sucede con otras divinidades hispanas, hecho señalado repetidamente por Vázquez Hoys, como Hércules, Silvano, las divinidades celestes Venus y Diana ${ }^{43}$.

Partiendo de la hipótesis de la permanencia del sustrato prerromano podriamos comprender las particularidades constructivas del llamado Capitolio de Baelo Claudia, en la provincia de Cádiz. Sus tres templos separados entre sí, tienen solamente un paralelo que conozcamos, en los templos del también Ilamado "Capitolio" de Sufetula ${ }^{44}$, en Túnez, aunque por el momento no se ha encontrado en ellos ninguna inscripción o estatua de culto que permita atribuir a un dios preciso dichos templos, aparte de que las tres cellae que lo forman tienen una cronología diferente y las particularidades de los cultos ibéricos, con el sincretismo de las divinidades femeninas prerromanas y romanas, señalado por A. Poveda y Vázquez Hoys y por esta autora en el caso de Artemis-Diana en Hispania, como ya hemos dicho arriba.

Es evidente la existencia de estos cultos en el sur de Hispania en época prerromana y suponemos que, de la misma forma que con la romanización no debió de haber un gran cambio en la población autóctona (aunque conocemos aportes de población itálica, señalada por autores clásicos y modernos), tampoco debió de haber grandes cambios en las creencias, perviviendo junto con la onomástica, la toponimia y los elementos materiales antes aludidos, el culto a divinidades prerromanas, entre las que se encontraban no sólo indígenas, sino orientales y púnicas, dándose a veces casos de sincretismo.

Cabe preguntarse, pues, si hemos atribuido los investigadores contemporáneos nombres romanos a divinidades prerromanas, por no valorar suficientemente una serie de factores que, como el oriental, norteafricano o púnico, dejaron su impronta en Hispania. Es posible que una onomástica latina esté encubriendo antiguas divinidades prerromanas. El caso de Júpiter parece el más patente, y no deja de ser sintomático que su culto se concrete en las zonas menos romanizadas de la Península. En muchas ocasiones tras

43 Véase el Hoyo, J., art. cit. MCV XXVIII/I, 1992, p. 70. Sobre estos sincretismos v. VÁZQUEZ HoYs, A. M ${ }^{2}$, Diana cit., pp. $31,40,425$, etc.; también VÁzQuez HoYs, A. Mª-PovedA, A.: "Pervivencia de las divinidades orientales y prerromanas en Hispania", IV Congreso Estudios Fenicios, Cádiz, 1995. En prensa.

44 Sobre Sufetula, cf. Duval, N. y Baratte, F., Les ruines de Sufetula, Sbeïtla. Societé Tunisienne de Diffussion. Tunis 1973. También BENDALA, M., "Capitolia Hispaniarum" en Anas 23. 1989, pp. 11-36. 
luppiter hemos de ver a la máxima divinidad masculina de una comunidad indígena, especialmente si la onomástica del dedicante es claramente indígena. Sólo en el mejor de los casos hemos podido llegar a concer realmente el nombre de esa divinidad camuflada, como en el caso de Eaecus ${ }^{45}$, pero en otros tan sólo la intuición nos hace suponer que exige un culto sincrético.

Algo parecido hemos de anotar sobre la asimilación de divinidades femenias que reúnen los atributos de fecundidad, maternidad y protección de la Tierra y de la Naturaleza, elementos comunes a todas las culturas mediterráneas. De este modo, la Mater Deum es asimilada con AtaecinaProserpina y con Victoria, pero también con Tanit y Ma-Bellona, con Artemis-Diana y con Juno. En este caso la numismática viene a confirmar las pistas tras las que la epigrafía nos coloca ${ }^{46}$.

Debe hacernos reflexionar asimismo la notación en epitafios latinos de divinidades no relacionadas directamente con la muerte, siendo tal vez el caso más significativo el de Venus, cuyo nombre se encuentra en la Península lbérica en dos epígrafes hallados en Tarragona y Almenara ${ }^{47}$. ¿Estamos, según opinión de Charles-Picard ${ }^{48}$ al encontrar a Venus en epitafios ante una Venus funeraria, que nosotros entendemos como un caso de asimilación con una divinidad siria, del tipo de las adoradas en Hispania por las comunidades orientales o norteafricanas antes mencionadas, o bien se trata de un caso de idealización de la difunta y asimilación con la divinidad, como postula P. Gros? ${ }^{49}$.

Estos y otros muchos problemas plantea el estudio de la religión romana en Hispania, quedando su solució en meras hipótesis de trabajo. Esperemos que nuestro interés y esfuerzo, así como el de los investigadores centrados en el tema, puedan en el futuro contribuir a desentrañarlos en pro del mejor conocimiento de nuestro pasado histórico.

45 FERnÁNDEz FÚSTER, L., "Eaecus. Aportación al estudio de las religiones primitivas hispánicas", AEA 1955, pp. 318-321.

46 Garcia-BELLIDO, Ma.P., “Las religiones orientales en la Península lbérica: Documentos numymásticos, l», AEA 64, 1991, pp. 37-81; VÁZQUEZ HoYS, A.M": "A propósito de la serpiente en las cerámicas ibéricas de Elche", Actas del XXII CNA, págs. 1-8; id.: Diana en la religiosidad hispanorromana I (Las fuentes. Las diferentes diosas). Madrid, 1995, desarrolla esta tesis de la persistencia y asimilación de divinidades femeninas prerromanas, púnicas y orientales, con divinidades romanas. Lo mismo para las divinidades masculinas del tipo Estimum-Asclepio-Esculapio en "La serpiente en la epigrafía hispana", Homenaje a M. Le Glay, Bruselas, 1994, pp. 568-582, lo que está muy en consonancia con la permisividad religiosa romana, que asimila los diferentes dioses, romanizándolos, sin mayor problema. También VAZOUEZ-POVEDA cit. supra.

47 ClL II 6054 (Sagunto) y C/L II 4415 (Tarragona).

48 Les religions de l'Afriuque antique, París, 1954, pp. 93-94.

49 Sobre Venus en epitafios, cf. GROS, P., Aurea templa. Recherches sur l'architecture religieuse de Rome à l'époque d'Auguste (Befar 231. Roma 1976) p. 40 no 302 y Grimal, P., "Venus et l'inmortalité", Hommage à Walter Deonna, col. Latomus XXVIII, 1957, p. 258. 